ORIGINAL ARTICLE

\title{
Influence of glutathione $S$-transferase gene polymorphisms on busulfan pharmacokinetics and outcome of hematopoietic stem-cell transplantation in thalassemia pediatric patients
}

\author{
M Ansari ${ }^{1,2,9}$, P Huezo-Diaz ${ }^{1,2,9}$, MA Rezgui ${ }^{3}$, S Marktel ${ }^{4}$, M Duval $^{3,5}$, H Bittencourt $^{3,5}$, B Cappelli ${ }^{6,7}$ and M Krajinovic ${ }^{3,5,8}$
}

\begin{abstract}
Hematopoietic stem-cell transplantation (HSCT) is currently the only curative therapeutic option for the treatment of thalassemia. In spite of the high cure rate, HSCT can lead to life-threatening adverse events in some patients. Busulfan (Bu) is a key component of the conditioning regimen prior to HSCT. Inter-individual differences in Bu pharmacokinetics (PK) are hypothesized to influence Bu efficacy and toxicity. Since Bu is mainly metabolized by glutathione S-transferase (GST), we investigated the relationship of GSTA1 and GSTM1 genotypes with first-dose PK and HSCT outcomes in 44 children with thalassemia intermedia and thalassemia major. All children received a myeloablative conditioning regimen with IV Bu. Association analysis revealed a relationship between GSTA169C $>T$ (or haplotype ${ }^{*} A /{ }^{*} B$ ) and first Bu dose PK that was dependent on sex and Pesaro risk classification (PRC). Among female patients and patients with PRC I-II, homozygous individuals for the GSTA1T - 69 allele defining haplotype ${ }^{*} B$, had higher Bu exposure and lower clearance $(P \leqslant 0.01)$. Association with HSCT outcomes showed that patients with the GSTM1 null genotypes had higher occurrence of regimen-related toxicity $(P=0.01)$. These results suggest that GST genotypes could be useful to tailor the first Bu dose accordingly to improve HSCT outcome.
\end{abstract}

Bone Marrow Transplantation (2016) 51, 377-383; doi:10.1038/bmt.2015.321; published online 21 December 2015

\section{INTRODUCTION}

The annual estimate of newborns affected by thalassemia is 40000 with a high prevalence in Mediterranean countries, Middle East and South Asia. ${ }^{1}$ Thalassemia syndrome is divided into two main groups, $\alpha$ and $\beta$ thalassemia and subdivided into four syndromes: thalassemia major $(\mathrm{Hb}<7 \mathrm{~g} / \mathrm{dL}$ and marked splenomegaly), intermediate ( $\mathrm{Hb} 7-10 \mathrm{~g} / \mathrm{dL}$ and splenomegaly), minor ( $\mathrm{Hb}>10 \mathrm{~g} / \mathrm{dL}$ and mild splenomegaly) and thalassemia trait (without abnormal clinical features). For the most severe forms of thalassemia, hematopoietic stem-cell transplantation (HSCT) is currently the only curative therapeutic option ${ }^{2,3}$ with busulfan $(\mathrm{Bu})$ as the key component of the myeloablative regimen prior to $\mathrm{HSCT}^{3}$ Recently, alternative alkylating agents, such as treosulfan, have also been successfully used in the conditioning regimen of patients with thalassemia. ${ }^{4,5}$ Inter-individual differences in $\mathrm{Bu}$ pharmacokinetics (PK) have been shown to affect Bu efficacy leading to toxicity or graft failure, even when administered IV., High Bu exposure (area under the curve, AUC $>1500 \mu \mathrm{mol} / \mathrm{min}$ or steady state concentration, Css $>900 \mathrm{mg} / \mathrm{kg}$ ) has been associated with greater toxicity and acute GvHD (aGvHD), whereas low exposure (AUC $<900 \mu \mathrm{mol} / \mathrm{min}$ or Css $<600 \mathrm{mg} / \mathrm{kg}$ ) has been associated with graft rejection or relapse. ${ }^{8-10} \mathrm{Bu}$ is metabolized by the liver cytosolic glutathione $S$-transferases (GSTs); ${ }^{11}$ GSTA1 is the predominant isoform of GST catalyzing the conjugation of $\mathrm{Bu}$ with glutathione (GSH), whereas GSTM1-1 and GSTP1-1 contribute to 46 and $18 \%$ of the activity of GSTA1, respectively..$^{12-15}$ We recently showed that the GST gene variants, particularly GSTA1 and GSTM1, influence Bu PK and outcomes of HSCT in children who underwent transplantation for both malignant and nonmalignant diseases. ${ }^{16,17}$ In the 1980s, the Pesaro group developed a prognostic scheme related to iron burden, which is used today to predict transplant outcome in patients younger than 17 years, known as the Pesaro risk classification (PRC). ${ }^{18}$ However, this scheme is unable to predict adverse events, such as aGvHD that can be as high as $20 \% .^{19}$ Additional prognostic tools are thus needed to prevent regimen-related toxicities (RRTs), including aGvHD, sinusoidal obstruction syndrome (SOS), hemorrhagic cystitis and lung toxicity.

Here, we extended our investigation to address the role of the GST genotypes in relation to Bu PK and pharmacodynamics to a homogeneous pediatric population of the Middle East affected by thalassemia, and addressed the relationship of the GSTA1 and GSTM1 genotypes with first Bu dose PK and with HSCT outcomes, retrospectively.

\section{PATIENTS AND METHODS}

Patients

This study comprised 44 children (21 males and 23 females, median age 8 ), including 9 patients with transfusion-dependent thalassemia intermedia $(20.5 \%)$ and 35 with thalassemia major (79.5\%) who underwent allogeneic HSCT between December 2005 and December 2010 at the Pediatric Immunohematology and Bone Marrow Transplantation Unit, San Raffaele

\footnotetext{
${ }^{1}$ Department of Pediatrics, Onco-Haematology unit, Geneva University Hospital, Faculty of Medicine, Geneva, Switzerland; ${ }^{2}$ Department of Pediatrics, CANSEARCH Research Laboratory, Faculty of Medicine, University of Geneva, Geneva, Switzerland; ${ }^{3}$ Charles-Bruneau Cancer Center, CHU Sainte-Justine Research Center, Montreal, Quebec, Canada; ${ }^{4}$ Stem Cell Programme, IRCCS, San Raffaele Scientific Institute, Milano, Italy; ${ }^{5}$ Department of Pediatrics, University of Montreal, Montreal, Quebec, Canada; ${ }^{6}$ Pediatric ImmunoHematology and BMT unit, IRCCS San Raffaele Hospital, Milano, Italy; ${ }^{7}$ Eurocord-Monaco, Centre scientifique de Monaco, Monaco, Principality of Monaco and ${ }^{8}$ Department of Pharmacology, Faculty of Medicine, University of Montreal, Montreal, Quebec, Canada. ${ }^{9}$ These authors contributed equally to this work. Correspondence: Dr P Huezo-Diaz Curtis, Department of Pediatrics, CANSEARCH Research Laboratory, Faculty of Medicine, University of Geneva, 64 Avenue de la Roseraie, 1205 Geneva, Switzerland.
} 
Scientific Institute, Milan, Italy. Before transplantation, patients were assigned to one of the three classes of risk (PRC), proposed by Lucarelli et $a .^{20}$ on the basis of iron chelation therapy, liver enlargement or evidence of portal fibrosis by liver biopsy. One patient was assigned to class I (2.3\%), 23 patients to PRC II (52.3\%) and 20 patients to PRC III (45.5\%). All parents provided informed consent for study participation. The demographic characteristics of the patients, and details of disease and transplantation are given in Table 1. The study is part of the European Bone Marrow Transplantation (EBMT) clinical trial (NCT01257854).

\section{Treatment regimen}

All patients received Bu-based myeloablative conditioning regimen prior to HSCT. IV Bu (Busilvex, Pierre Fabre Laboratory, Paris, France) was administered as a 2-h infusion in 16 doses every $6 \mathrm{~h}$ from day -9 to -6 . For the first $\mathrm{Bu}$ dose, five different doses based on weight were given according to the standard protocol: ${ }^{21} 1 \mathrm{mg} / \mathrm{kg}$ for $<9 \mathrm{~kg} ; 1.2 \mathrm{mg} / \mathrm{kg}$ for $\geqslant 9$ and $<16 \mathrm{~kg} ; 1.1 \mathrm{mg} / \mathrm{kg}$ for $\geqslant 16$ and $\leqslant 23 \mathrm{~kg} ; 0.95 \mathrm{mg} / \mathrm{kg}$ for $>23$ and

Table 1. Characteristics of patients $(n=44)$, disease and treatment

\begin{tabular}{|c|c|c|}
\hline \multirow[t]{2}{*}{ Characteristics } & \multicolumn{2}{|c|}{ Patients } \\
\hline & $\mathrm{N}$ & $\%$ \\
\hline \multicolumn{3}{|l|}{ Gender } \\
\hline Male & 21 & 47.7 \\
\hline Female & 23 & 52.3 \\
\hline \multicolumn{3}{|l|}{ Population } \\
\hline Middle East & 44 & 100 \\
\hline \multicolumn{3}{|l|}{ Diagnosis } \\
\hline Thalassemia intermedia & 9 & 20.5 \\
\hline Thalassemia major & 35 & 79.5 \\
\hline \multicolumn{3}{|l|}{ Pesaro risk classification } \\
\hline Class I (low risk) & 1 & 2.3 \\
\hline Class II (intermediate risk) & 23 & 52.3 \\
\hline Class III (high risk) & 20 & 45.5 \\
\hline \multicolumn{3}{|l|}{ HLA compatibility } \\
\hline s.d. & 44 & 100 \\
\hline \multicolumn{3}{|l|}{ Stem cell source } \\
\hline $\mathrm{BM}$ & 44 & 100 \\
\hline \multicolumn{3}{|l|}{ Conditioning $^{a}$} \\
\hline $\mathrm{Bu} / \mathrm{Cy}$ & 44 & 100 \\
\hline \multicolumn{3}{|l|}{ Serotherapy } \\
\hline No & 28 & 63.6 \\
\hline ATG & 16 & 36.4 \\
\hline \multicolumn{3}{|l|}{ GvHD prophylaxis } \\
\hline CSA+MTXX & 16 & 36.4 \\
\hline \multirow[t]{2}{*}{ CSA+MTX+steroids } & 28 & 63.6 \\
\hline & Median & Range \\
\hline Nucleated cells $\left(\times 10^{8} / \mathrm{kg}\right)$ & 4.90 & $1.40-11.50$ \\
\hline $\mathrm{CD}^{4} 4^{+}$cells $\left(\times 10^{8} / \mathrm{kg}\right)$ & 0.0814 & $0.036-0.216$ \\
\hline Age (years) & 8 & $1.5-17$ \\
\hline Weight (kg) & 22.50 & $11.50-47.0$ \\
\hline Height (cm) & 124.50 & $94.0-162.0$ \\
\hline BMI $\left(\mathrm{kg} / \mathrm{m}^{2}\right)$ & 16.022 & $11.31-19.71$ \\
\hline BSA $\left(m^{2}\right)$ & 0.88 & $0.54-1.45$ \\
\hline \multicolumn{3}{|c|}{$\begin{array}{l}\text { Abbreviations: } \mathrm{ATG}=\text { anti-thymocyte globulin; } \mathrm{BM}=\text { bone marrow; } \\
\mathrm{BMI}=\text { body mass index; BSA=body surface area; Bu=busulfan; } \\
\mathrm{CSA}=\text { cyclosporine } \mathrm{A} ; \mathrm{Cy}=\mathrm{cyclophosphamide;} \mathrm{MTX}=\text { methotrexate; s.d.= } \\
\text { sibling donor. }{ }^{\text {T}} \text { Therapeutic drug concentration monitoring was performed } \\
\text { at dose } 1 \text {, and Bu dose was adjusted for each patient accordingly from } \\
\text { dose } 4 \text { onwards. }\end{array}$} \\
\hline
\end{tabular}

$\leqslant 34 \mathrm{~kg}$; and $0.8 \mathrm{mg} / \mathrm{kg}$ for $>34 \mathrm{~kg}$. PK-guided dose adjustment was performed whereby calculation of the total AUC was based on plasma blood samples at 0, 2, 3, 4 and $6 \mathrm{~h}$ after the first dose. Bu AUC values $>900$ and $<1500 \mu \mathrm{mol} / \mathrm{min}$ were considered to lie within the therapeutic window. The $\mathrm{Bu}$ dose was adjusted from dose 5 using the following equation: adjusted dose $=$ actual dose $\times$ target AUC/actual AUC (target AUC $=1250 \mu \mathrm{mol} / \mathrm{min}$ ). ${ }^{22}$ The conditioning regimen for patients in the PRC groups I-II was composed of IV Bu (detailed above), and cyclophosphamide $200 \mathrm{mg} / \mathrm{kg}$ total dose (days -5 to -2 ) for patients aged $\geqslant 4$ years; thiotepa $10 \mathrm{mg} / \mathrm{kg}$ (day -6 ) was added for patients aged $<4$ years. For patients in PRC III, the regimen began with a preconditioning regimen composed of hydroxyurea $30 \mathrm{mg} / \mathrm{kg}$ daily, azathioprine $3 \mathrm{mg} / \mathrm{kg}$ daily (days -45 to -11 ) and fludarabine $100 \mathrm{mg} / \mathrm{m}^{2}$ total dose (days -17 to -13) followed by a main conditioning regimen that included either IV Bu and cyclophosphamide $160 \mathrm{mg} / \mathrm{kg}$ total dose (days -5 to -2 ) or IV Bu, cyclophosphamide $160 \mathrm{mg} / \mathrm{kg}$ and anti-thymocyte globulin $7.5-10 \mathrm{mg} / \mathrm{kg}$ total dose (days -7 to -4 ). ${ }^{22}$ GvHD prophylaxis consisted of oral cyclosporine A adjusted to a trough plasma level of $150-250 \mathrm{ng} / \mathrm{mL}$. In the absence of GvHD, cyclosporine A was tapered from day 60 until discontinuation at 1 year. Associated to a short course of IV methotrexate $10 \mathrm{mg} / \mathrm{m}^{2}$ on days 1,3 and 6 . Additional GvHD prophylaxis consisted of methylprednisolone $0.5 \mathrm{mg} / \mathrm{kg}$ from day -1 to 25 alone or associated to anti-thymocyte globulin. This protocol followed the recommendation by Sodani et al. ${ }^{23}$ Anti-thymocyte globulin $(7.5 \mathrm{mg} / \mathrm{kg}$ total) was given to 16 patients in risk group III. Details of treatment regimen are presented in Table 1.

\section{Definition of clinical outcomes}

Hematopoietic recovery was defined as absolute neutrophil count $\geqslant 0.5 \times 109$ per liter for the first three consecutive days, and platelet count $\geqslant 50 \times 109$ per liter for the first 10 consecutive days from the day of transplant. ${ }^{16}$ In short, SOS was diagnosed according to the criteria of McDonald et al., ${ }^{24}$ and aGvHD is based on quantification of skin rash, serum bilirubin, diarrhea and persistent nausea according to the 1994 Consensus Conference on aGvHD Grading. ${ }^{25}$ Lung toxicity is revealed by multilobar infiltrates indicated by chest X-ray or computed tomography scan, clinical signs of pneumonia along abnormal pulmonary physiology with absence of active respiratory tract infection. ${ }^{26}$ Overall survival was the time between day of transplant and death due to any cause, whereas event-free survival was the time from day of transplant to the day of occurrence of any event, that is, death or graft rejection whichever is seen first. Regimen related toxicity (RRT) was defined as the occurrence of any of the following complications: SOS, aGvHD grade I-IV, lung toxicity, hemorrhagic cystitis (HC) before day 180 post-transplant whichever is seen first. Details of clinical outcomes are shown in Table 2.

Table 2. Clinical outcomes observed in the study subjects $(n=44)$

\begin{tabular}{lcc}
\hline Clinical outcomes & $\begin{array}{c}\text { Cumulative } \\
\text { incidence }\end{array}$ & Day of onset \\
& $\mathrm{N}(\%)$ & Median (range) \\
\hline Neutrophil recovery (day 100) & $41(93.2)$ & $19(12-33)$ \\
Platelet recovery (day 180) & $39(88.6)$ & $27(13-75)$ \\
Sinusoidal obstruction & $1(2.3)$ & $22(22)$ \\
syndrome & $15(34.1)$ & $25(13-112)$ \\
Acute GvHD (grade I-IV) & $5(11.36)$ & $24.2(13-35)$ \\
Acute GvHD (grade II-IV) & $5(11.4)$ & $36(15-52)$ \\
Lung toxicity & $1(2.3)$ & $39(33-45)$ \\
Hemorrhagic cystitis & $3(6.8)$ & $48(13-67)$ \\
Death & $7(15.9)$ & $322.5(23-365)$ \\
Graft rejection & $8(18.2)$ & $1805(23-365)$ \\
Event & & \\
\% Of donor cell chimerism, day $100(\mathrm{n}=40)$ & $61(30-78)$ \\
$\quad 395 \%$ & $32(72.8)$ & $62(40-69)$ \\
$\geqslant 50-\leqslant 95 \%$ & $7(11.3)$ & $\mathrm{NA} \mathrm{NA}$ \\
$\quad<50 \%$ & $1(2.3)$ &
\end{tabular}


PK analysis and genotyping

$\mathrm{Bu}$ levels after the first $\mathrm{Bu}$ dose were measured using an established analytical method, and the PK parameters were estimated using non-compartmental analysis (WinNonlin, version 3.1, Pharsight, Montreal, QC, Canada). ${ }^{16,22}$ PK data are represented in terms of maximum plasma concentration (Cmax), AUC, Css and clearance (CL) provided in Supplementary Table 1. Patients were genotyped for the common polymorphisms in the GSTA1 (C-69 T, A-513G, G-631 T and C-1142G) by allele-specific oligonucleotide hybridization (ASO), as previously described. ${ }^{27}$ GSTM1 null alleles were detected by gel electrophoresis. ${ }^{28,29}$

\section{Statistics}

Association analyses were performed with individual polymorphisms as well as with GSTA1 haplotypes (Supplementary Table 2). Bu PK parameters (Cmax, AUC, Css and CL) and dose adjustment (ratio of adjusted vs unadjusted dose) were compared between genotypes or between carriers and non-carriers of GSTA1 haplotypes using linear regression analysis. When applicable, log-transformed values were used to normalize the data.

Event-free survival was estimated by Kaplan-Meier curves, and log-rank test was used to compare the survival differences between genotype or PRC groups. The cumulative incidence of engraftment, aGvHD or RRT in relation to the GST genotypes was estimated by 1-survival curves using Kaplan-Meier analysis and log-rank test. Univariate Cox regression analysis was used to estimate hazard ratio with a $95 \%$ confidence interval. Haplotypes (Supplementary Table 2) were resolved using PHASE (version 2.1, Chicago, IL, USA). ${ }^{30}$ Statistical analyses were performed with SPSS statistics (version 19, SPSS Inc., New York, NY, USA).

The chi-square test (for categorical variables) and linear regression (for continuous variables) were used to explore correlations between patient characteristics (that is, Pesaro class, age, gender, weight, aGvHD prophylaxis, the number of $\mathrm{CD}_{3} 4^{+}$and nucleated cells infused) and $\mathrm{Bu} \mathrm{PK}$ or clinical outcomes.

\section{RESULTS}

HSCT clinical outcome

Among clinical outcomes analyzed, 15 patients had aGvHD grade I-IV, 5 had aGvHD grade II-IV, 5 had lung toxicity, 1 patient developed SOS, 1 had hemorrhagic cystitis, 7 patients had graft failure and 3 patients died. Neutrophil recovery occurred in 41 and platelet recovery in 39 patients (Table 2 ).

\section{Bu PK studies}

The median $\mathrm{Bu}$ Css after the first dose was $823.5 \mathrm{ng} / \mathrm{mL}$ (420-2126 ng/mL; Supplementary Table 1). The PK studies after the first IV Bu dose showed that 24 patients (54.5\%) achieved a Css within the therapeutic range $(600-900 \mathrm{ng} / \mathrm{mL}), 7$ patients $(15.9 \%)$ had a Css below the lower target limit and 13 patients (29.5\%) had a Css above the upper target limit.

No significant correlation was found between Bu Css and specific pretransplantation clinical features such as PRC group $(P=0.8)$, age $(P=0.8)$, gender $(P=0.1)$ or weight $(P=0.7)$.

\section{Genetic variants of GSTA1, M1 and Bu PK}

The minor allele frequencies of the GSTA1 polymorphisms and haplotypes are shown in Supplementary Table 2. The GSTM1 null genotype was seen in $61 \%$ of patients $(n=27)$, higher than the frequency of $43 \%$ seen in Caucasians. ${ }^{16,31}$ Association analysis between the GSTA1 genotypes/haplotypes and Bu PK after the first $\mathrm{Bu}$ dose revealed significant association of Css and AUC with GSTA1-69 C>T and - $1142 C>G$ polymorphisms $(P=0.03$ and 0.02 , respectively). The $T$ allele of $-69 C>T$ defines haplotype ${ }^{*} B$ (all haplotypes ${ }^{*} B$ combined) and the $G$ allele of $-1142 C>G$ defines the most frequent ${ }^{*} B$ haplotype, ${ }^{*} B 1$ (Supplementary Table 2). Given that the frequencies of -69 and -1142 substitutions were comparable and similar results were obtained for these polymorphisms and resulting haplotypes, the results are presented for the $-69 C>T$ only (Figure 1 ). Individuals with the $\Pi T-69$ genotype (or ${ }^{*} B^{*} B$ haplotype) had significantly higher first
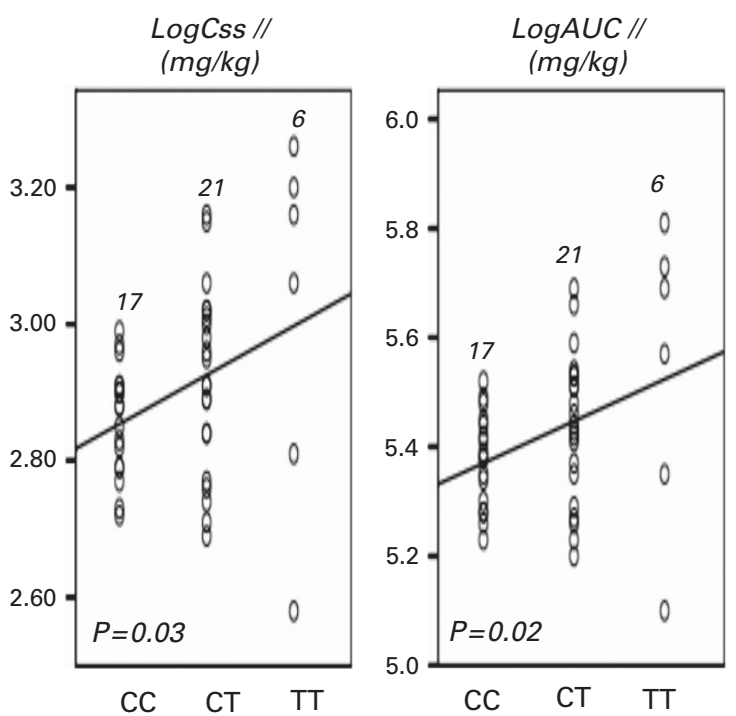

Figure 1. Influence of GSTA1 C-69T on the first dose of Bu pharmacokinetics. The pharmacokinetic parameters of $\mathrm{Bu}$ in relation to $C C, C T$ and $T T$ genotypes in all studied patients. Respective mean $\pm S D$ values adjusted for $B u$ dose $(\mathrm{mg} / \mathrm{kg})$ are for logCss (steady state concentration): $2.9 \pm 0.08,2.9 \pm 0.1$ and $3.0 \pm 0.3$, and for logAUC (area under the curve): $5.4 \pm 0.09,5.4 \pm 0.1$ and $5.5 \pm 0.3$. The number of individuals represented for each genotype group as well as $P$-values for the difference across groups is given on each plot.

Bu Css compared to individuals with the CC genotype (or ${ }^{*} A{ }^{*} A$ haplotype combination). Since we previously noted that an association between the GSTA1 and PK was more apparent in female patients, ${ }^{16}$ we also performed the analysis following stratification by sex. In girls, there was a linear relationship between Bu levels and GSTA1 genotype; Bu levels increased with the number of $T-69$ alleles (Cmax, $P=0.001$; Css, $P<0.0005$; AUC, $P<0.0005$; Figure 2a), consequently $\mathrm{CL}$ decreased and was slowest in $\Pi$ individuals $(P=0.006$; Figure 2a). The GSTA1-PK association seems to be also modulated by the PRC classes. In PRC I and || patients only, was there an association with GSTA1 genotypes and $\mathrm{Bu} \mathrm{PK}$, after the same gene-dosage effect (Cmax, $P=0.01 ;$ Css, $P=0.002 ; \quad A U C, P=0.001 ; \quad C L=P=0.01$; Figure 2b). Ratio of adjusted to unadjusted $\mathrm{Bu}$ dose was also found to correlate significantly with GSTA1 -69 polymorphism, demonstrating a linear relationship $(P=0.008$; Figure 3$)$; individuals with the $\pi$ genotype required more often reduction of Bu dose. There was no association between GSTM1 genotypes and PK, except a marginal association with $\mathrm{CL}(P=0.05$, not shown). There was no association between dose adjustment and GSTM1 genotypes.

Genetic variants of GSTA1, M1 and clinical outcomes of HSCT Analysis between genotypes and outcomes showed that patients with GSTM1 null genotype had a higher occurrence of RRT compared to patients carrying GSTM1 non-null genotype ( $P=0.01$, hazard ratio $=4.28$, confidence interval $=1.23-14.9$; Figure $4 \mathrm{a}$ ), mostly due to an increase in aGvHD cases $(P=0.01$; Figure $4 \mathrm{~b})$. No other significant association between GST genotypes/haplotypes and HSCT outcomes was seen.

HSCT clinical outcomes in relation to pretransplantation characteristics, dose adjustment and PK

Event-free survival differed between the PRC classes with class III showing the lowest event-free survival ( $P=0.009$, not shown) due to graft rejection. 

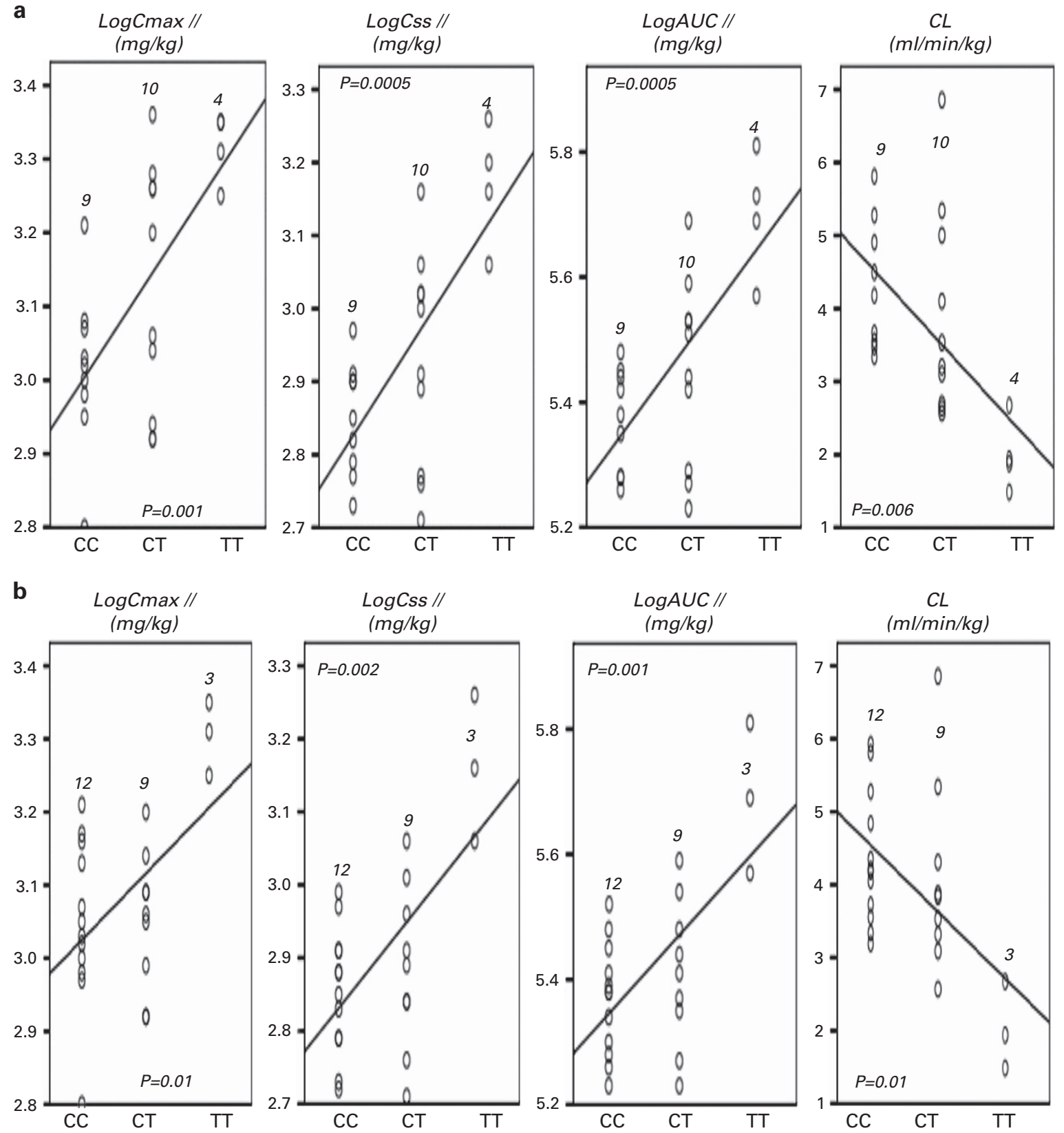

Figure 2. Influence of GSTA1C-69 T genotypes on Bu pharmacokinetics according to sex and Pesaro risk classification. (a) The pharmacokinetic parameters of Bu in female patients with CC, CT and $\Pi$ genotypes. Respective mean \pm SD values adjusted for Bu dose (mg/kg) are for logCmax (maximum plasma concentration): $3.0 \pm 0.1,3.1 \pm 0.2$ and $3.3 \pm 0.05$; for logCss: $2.8 \pm 0.07,2.9 \pm 0.1$ and $3.2 \pm 0.08$; for logAUC: $5.4 \pm 0.08$, $5.5 \pm 0.1$ and $5.7 \pm 0.1$; and for $\mathrm{CL}$ per kg (clearance): $4.3 \pm 0.9,3.9 \pm 1.4$ and $2.0 \pm 0.5$. (b)The pharmacokinetic parameters of Bu in patients assigned to Pesaro class I-II with CC, CT and $T$ genotypes. Respective mean \pm SD values adjusted for Bu dose (mg/kg) are for logCmax: $3.0 \pm 0.1,3.1 \pm 0.09$ and $3.3 \pm 0.05$; for logCss: $2.9 \pm 0.09,2.9 \pm 0.1$ and $3.2 \pm 0.1$; for logAUC: $5.4 \pm 0.09,5.4 \pm 0.1$ and $5.7 \pm 0.1$; and for CL per kg: $4.4 \pm 0.9,4.1 \pm 1.3$ and $2.0 \pm 0.6$.

No significant correlation was found among RRT with Pesaro risk $(P=0.6)$, aGvHD prophylaxis $(P=0.9)$, anti-thymocyte globulin serotherapy $(P=0.5)$, number of $\mathrm{CD}^{+} 4^{+}$and nucleated cells infused $(P=0.7$ and $P=0.5$, respectively), age $(P=0.5)$, gender $(P=0.7)$ or weight $(P=0.1)$.

Analysis of ratio of adjusted to unadjusted dose with clinical outcomes showed that patients with aGvHD had a more frequent increase of Bu dose $(P=0.02$ for aGvHD I-IV and $P=0.001$ aGvHD II-IV; Figure 5a), whereas patients with graft failure had their $\mathrm{Bu}$ dose decreased more frequently $(P=0.04$; Figure 5a). In accordance with this, aGvHD occurred more frequently in patients with the first dose of Css $<600 \mathrm{ng} / \mathrm{mL}$ $(P \leqslant 0.01$; Figure $5 b)$, whereas the graft failure was more common for individuals with first dose of Css $>900 \mathrm{ng} / \mathrm{mL} \quad(P=0.05$; Figure $5 b$ ).

\section{DISCUSSION}

The Pesaro risk scheme has previously been shown to successfully predict poor outcome and graft failure in thalassemia patients after an HSCT. ${ }^{18,32}$ The incidence and severity of aGvHD were nevertheless similar in the three Pesaro categories, suggesting ${ }^{19}$ 
that additional factors are needed to predict and prevent HSCT-associated adverse events. All patients within this study were 10/10 HLA matching with their donors, and there were also no significant correlations with other features (aGvHD prophylaxis, the number of $\mathrm{CD}_{3} 4^{+}$and nucleated cells infused), hence allowing for a better exploration of the relationship between myeloablative regimen and genetic determinants.

We studied the association of genetic variants within the GSTA1 and GSTM1 genes with Bu PK after the first dose, Bu dose adjustment and clinical outcomes of HSCT in patients with thalassemia. Association analysis examining GSTA1 and GSTM1 genotypes against Bu PK revealed an association with GSTA1 - 69 $C>T$ (or haplotype ${ }^{*} A /{ }^{*} B$ ), in a gene-dose additive manner. The ${ }^{*} A$ haplotype correlated with lower Bu plasma levels and faster CL. This association was sex and PRC class dependent,

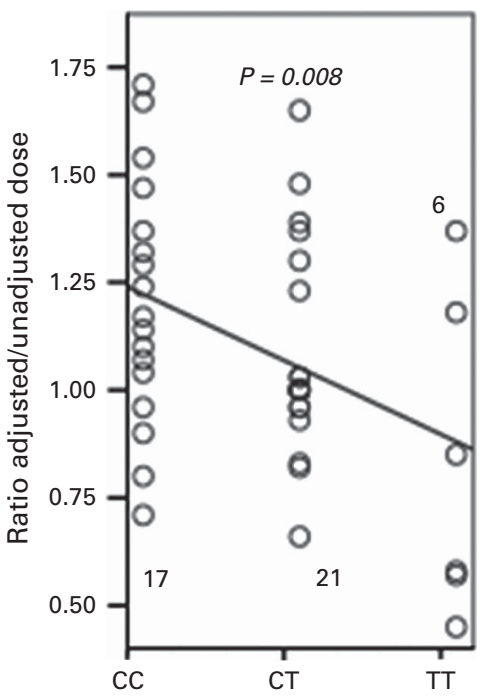

Figure 3. Correlation between dose adjustment and GSTA1-69 genotypes. Dose adjustment presented as ratio of adjusted vs unadjusted Bu dose in relation to $C C, C T$ and $T T$ genotypes in all studied patients. Respective mean $\pm S D$ values are $C C=1.21 \pm 0.29$, $C T=1.08 \pm 0.05$ and $T=0.83 \pm 0.15$. The number of individuals represented for each genotype group as well as $P$-values for the difference across groups is given on each plot. whereby the association was more apparent in the female patients and in patients assigned to PRC I and II risk groups. The observed correlation between $G S T A{ }^{*} A{ }^{*} B$ haplotypes and $P K$ is in accordance with the functional studies, suggesting lower GSTA activity in GSTA ${ }^{*} B$ carriers and higher activity in ${ }^{*} A$ carriers. ${ }^{33,34}$ It is also supported by several studies that reported decreased $\mathrm{CL}$ after IV $\mathrm{Bu}$ in pediatric GSTA*B patients. ${ }^{31,35,36}$ We recently reported lower Bu exposure in children with GSTA1 ${ }^{*} A 2$ haplotype who underwent HSCT for malignant (majority of cases) and non-malignant diseases and consequently, higher $\mathrm{Bu}$ levels in patients without this haplotype. ${ }^{16}$ Given that the large majority of patients without haplotype ${ }^{*} A 2$ are haplotype ${ }^{*} B$ carriers, there is a good concordance between the two studies. Like to our previous observation, ${ }^{16}$ we noted the sex-dependent relationship between GSTA1 genotype and PK that might be related to the reported difference in cytosolic GST activity between males and females. ${ }^{37}$ The association was also more apparent in PRC class I-II patients that may be related to liver status. Pesaro risk group III patients have a higher degree of liver damage due to transfusion-related iron overload, possibly confounding the effects of GST functional polymorphisms with transfusion-induced GST damage. Nevertheless, the finding with PRC I and II classes is in accordance with the studies that have shown a relationship between GSTA1 genotypes and the PK following first Bu dose in children with hemoglobinopathies. ${ }^{36,38,39}$ We also noticed a correlation between dose adjustment and GSTA1 - 69 genotypes, which follows the pattern of association seen between this genotype and PK. There was only a marginal association between the GSTM1 variant and Bu PK in our study group. Considering the role of GSTM1 genotype in hemoglobinopathies and thalassemia, the studies conducted so far have demonstrated conflicting results. Higher and lower Bu exposure in GSTM1 null individuals as well as an absence of association have all been reported. ${ }^{36,40}$ Reasons for such variability may be due to the differences in population studied and lack of homogeneity in terms of diagnosis and treatment regimen. ${ }^{38}$ Additional confounding factors or false positives cannot be ruled out.

In regard to the relationship between GST polymorphisms and clinical HSCT outcomes, we observed a higher frequency of RRT, mostly due to aGvHD cases, among patients with GSTM1 null genotype. This finding is in accordance with the report of Elhasid et al., ${ }^{39}$ and our previous study. ${ }^{16}$ GSTM1 null genotype seems to also predispose thalassemia patients to other complications such as higher occurrence of SOS reported by Srivastava et al. ${ }^{38}$ The

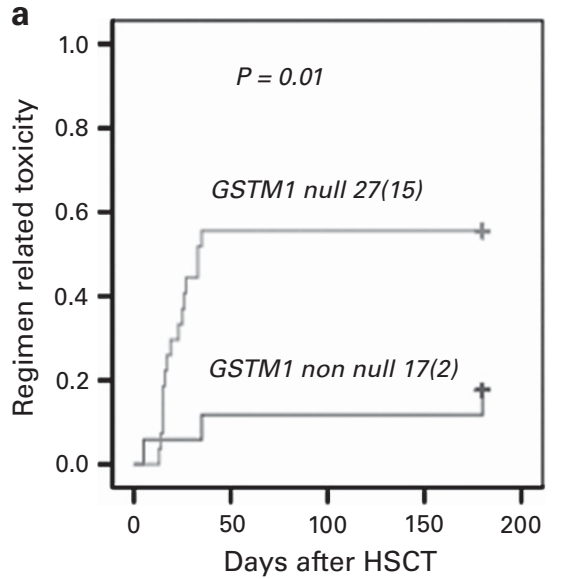

$\mathrm{HR}_{* \mathrm{GSTM} 1 \mathrm{null}}=4.28,95 \% \mathrm{Cl}=(1.23-14.9)$ b

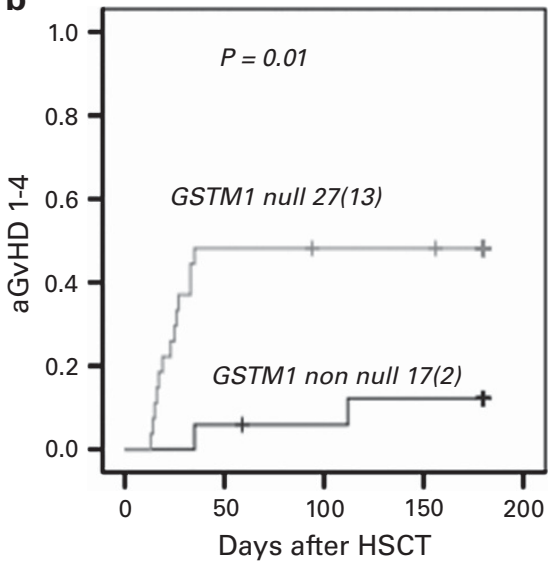

$\mathrm{HR}_{* \text { GSTM1null }}=5.65,95 \% \mathrm{Cl}=(1.23-25.1)$

Figure 4. Association of GSTM1 null genotype with (a) regimen-related toxicity (RRT) and (b) aGvHD. The number of patients in each curve with and without GSTM1 null genotype and number of individuals with (a) RRT or (b) aGvHD (given in the parenthesis), as well as the P-value, estimated by log-rank test for the cumulative RRT and aGvHD incidence between the genotype groups, are indicated on each plot. 


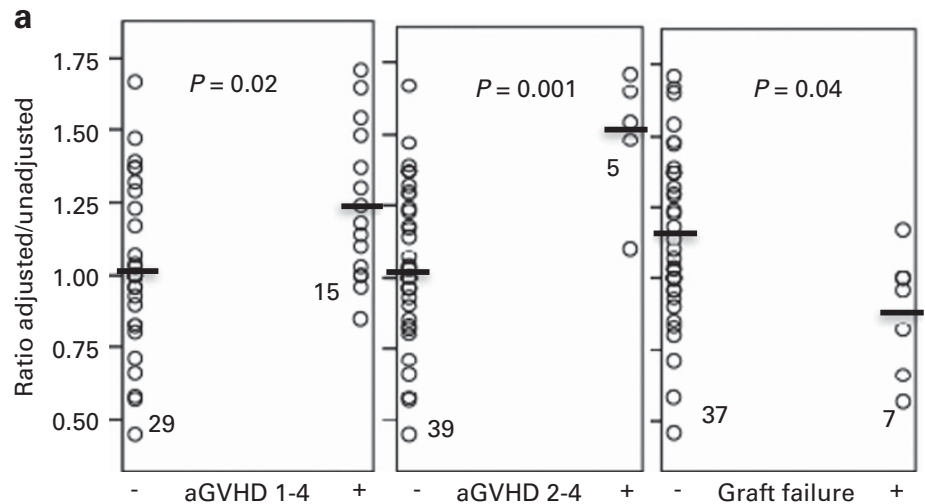

b
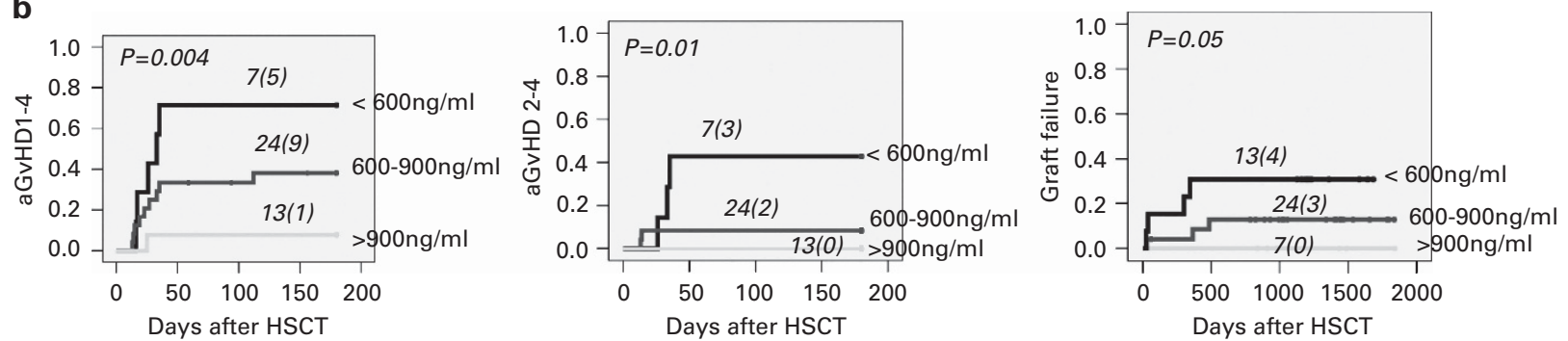

Figure 5. Correlation of dose adjustment in (a) and Css in (b) with aGvHD I-IV or aGvHD II-IV and graft failure (a). Presence and absence of a given complication is denoted by + and - sign, respectively. The dose adjustment is depicted by the ratio of adjusted vs unadjusted dose. Mean \pm SD values for dose adjustment are shown as horizontal lines across each group and for aGvHD I-IV are $1.02 \pm 0.29(-)$ and $1.24 \pm 0.03$ (+); for aGvHD II-IV are 1.04 $\pm 0.26(-)$ and $1.49 \pm 0.50(+)$; and for graft failure are $1.13 \pm 0.29(-)$ and $0.88 \pm 0.21$ (+). (b) Css is presented as categorical variable with Css $<600 \mathrm{ng} / \mathrm{mL}$, from 600 to $900 \mathrm{ng} / \mathrm{mL}$ and $>900 \mathrm{ng} / \mathrm{mL}$. The number of individuals represented for each genotype group as well as $P$-values for the difference across groups is given on each plot.

same finding is seen by Zwaveling et al., ${ }^{41}$ in a study with mixed malignant and non-malignant patients. In contrast, in a recent sickle-cell anemia study, no association was found. ${ }^{40}$ The relationship that we observed between aGvHD and GSTM1 null genotype is not supported by a GSTM1-Bu PK correlation suggesting different mechanisms contributing to this complication. For example, the concomitant medication (cyclophosphamide) could have lead to drug-drug interaction and influenced the drug-induced toxicity. ${ }^{42}$

We also noticed a correlation of dose adjustment, depicted by adjusted to unadjusted dose ratio with occurrence of aGvHD and graft failure, suggesting that perhaps overadjustment in both directions may have influenced onset of these complications in certain patients. This was further supported by correlation between these outcomes and Bu levels following the first dose. This observation nevertheless has to be taken with caution given that this effect could have been influenced by other factors, such as disease severity or concomitant medication. Given that GSTA1 correlated with PK, a similar relation between GSTA1 and clinical outcomes was noted; however, the association was not significant (not shown), which could be due to the low frequency of some clinical outcomes, lower frequency of ${ }^{*} B$ haplotype in this Middle Eastern population compared to Caucasians and modulation of the effect by non-genetic factors. The interplay between the GST polymorphisms with disease severity and patients' characteristics suggest that more studies on homogenous thalassemia patient populations are needed to estimate how best to incorporate genetic information in the existing models for Bu dose estimates.

In conclusion, our data show that the PRC system is still the best predictor of graft failure but it cannot predict Bu-induced RRT. Genetic variants of GST genes were shown to influence Bu PK and clinical outcomes of HSCT, especially aGvHD in children with thalassemia suggesting that the variability of Bu exposure and adverse events can partly be explained and predicted by genetic polymorphisms. By including dose adjustment in the analysis, a new question has been highlighted concerning dose adjustment strategies. This study provides further insights into the pharmacogenetics of $\mathrm{Bu}$, supporting the idea that genotyping of relevant variants combined with disease and patients' characteristics may potentially open the possibility of preventing overadjustments by providing better first Bu dose estimates.

\section{CONFLICT OF INTEREST}

The authors declare no conflict of interest.

\section{ACKNOWLEDGEMENTS}

We are thankful to all patients and their parents for consenting to participate in this genetic study. This work was supported by grants from the CANSEARCH foundation, The Dr Dubois-Ferrière Dinu Lipatti foundation, la Ligue Genevoise Contre le Cancer and the Swiss National Fund.

\section{REFERENCES}

1 Modell B, Darlison M. Global epidemiology of haemoglobin disorders and derived service indicators. Bull World Health Organ 2008; 86: 480-487.

2 Lucarelli G, Angelucci E. Allogeneic hematopoietic stem cell transplantation for thalassemia. In: Atkinson K, Champlin R, Ritz J, Fibbe WE, Ljungman P, Brenner MK (eds). Clinical bone marrow and blood stem cell transplantation. Cambridge University Press: Cambridge, 2004, pp 929-946.

3 Lucarelli G, Isgro A, Sodani P, Gaziev J. Hematopoietic stem cell transplantation in thalassemia and sickle cell anemia. Cold Spring Harb Perspect Med 2012; 2: a011825.

4 Bernardo ME, Piras E, Vacca A, Giorgiani G, Zecca M, Bertaina A et al. Allogeneic hematopoietic stem cell transplantation in thalassemia major: results of a reduced-toxicity conditioning regimen based on the use of treosulfan. Blood 2012; 120: 473-476.

5 Mathews V, George B, Viswabandya A, Abraham A, Ahmed R, Ganapule A et al. Improved clinical outcomes of high risk beta thalassemia major patients 
undergoing a HLA matched related allogeneic stem cell transplant with a treosulfan based conditioning regimen and peripheral blood stem cell grafts. PLOS ONE 2013; 8: e61637.

6 Dalle JH, Wall D, Theoret Y, Duval M, Shaw L, Larocque D et al. Intravenous busulfan for allogeneic hematopoietic stem cell transplantation in infants: clinical and pharmacokinetic results. Bone Marrow Transplant 2003; 32: 647-651.

7 Tran H, Petropoulos D, Worth L, Mullen CA, Madden T, Andersson B et al. Pharmacokinetics and individualized dose adjustment of intravenous busulfan in children with advanced hematologic malignancies undergoing allogeneic stem cell transplantation. Biol Blood Marrow Transplant 2004; 10: 805-812.

8 Vassal G, Michel G, Esperou H, Gentet JC, Valteau-Couanet D, Doz F et al. Prospective validation of a novel IV busulfan fixed dosing for paediatric patients to improve therapeutic AUC targeting without drug monitoring. Cancer Chemother Pharmacol 2008; 61: 113-123.

9 Andersson BS, Thall PF, Madden T, Couriel D, Wang X, Tran HT et al. Busulfan systemic exposure relative to regimen-related toxicity and acute graft-versus-host disease: defining a therapeutic window for i.v. BuCy2 in chronic myelogenous leukemia. Biol Blood Marrow Transplant 2002; 8: 477-485.

10 Malar R, Sjoo F, Rentsch K, Hassan M, Gungor T. Therapeutic drug monitoring is essential for intravenous busulfan therapy in pediatric hematopoietic stem cell recipients. Pediatr Transplant 2011; 15: 580-588.

11 Dirven HA, van Ommen B, van Bladeren PJ. Glutathione conjugation of alkylating cytostatic drugs with a nitrogen mustard group and the role of glutathione S-transferases. Chem Res Toxicol 1996; 9: 351-360.

12 Czerwinski M, Gibbs JP, Slattery JT. Busulfan conjugation by glutathione S-transferases alpha, mu, and pi. Drug Metab Dispos 1996; 24: 1015-1019.

13 Gibbs JP, Czerwinski M, Slattery JT. Busulfan-glutathione conjugation catalyzed by human liver cytosolic glutathione S-transferases. Cancer Res 1996; 56: 3678-3681.

14 Rowe JD, Nieves E, Listowsky I. Subunit diversity and tissue distribution of human glutathione S-transferases: interpretations based on electrospray ionization-MS and peptide sequence-specific antisera. Biochem J 1997; 325 (Pt 2): 481-486.

15 Cooper AJ, Younis IR, Niatsetskaya ZV, Krasnikov BF, Pinto JT, Petros WP et al. Metabolism of the cysteine $\mathrm{S}$-conjugate of busulfan involves a beta-lyase reaction. Drug Metab Dispos 2008; 36: 1546-1552.

16 Ansari M, Rezgui MA, Theoret Y, Uppugunduri CR, Mezziani S, Vachon MF et al Glutathione S-transferase gene variations influence BU pharmacokinetics and outcome of hematopoietic SCT in pediatric patients. Bone Marrow Transplant 2013; 48: 939-946.

17 Ansari M, Lauzon-Joset JF, Vachon MF, Duval M, Theoret $Y$, Champagne MA et al. Influence of GST gene polymorphisms on busulfan pharmacokinetics in children. Bone Marrow Transplant 2010; 45: 261-267.

18 Lucarelli G, Galimberti M, Polchi P, Angelucci E, Baronciani D, Giardini C et al. Bone marrow transplantation in patients with thalassemia. N Engl J Med 1990; 322: 417-421.

19 Gaziev D, Polchi P, Galimberti M, Angelucci E, Giardini C, Baronciani D et al. Graft-versus-host disease after bone marrow transplantation for thalassemia: an analysis of incidence and risk factors. Transplantation 1997; 63: 854-860.

20 Lucarelli G, Galimberti M, Giardini C, Polchi P, Angelucci E, Baronciani D et al. Bone marrow transplantation in thalassemia. The experience of Pesaro. Ann NY Acad Sci 1998; 850: 270-275.

21 Nguyen L, Fuller D, Lennon S, Leger F, Puozzo C. I.V. busulfan in pediatrics: a novel dosing to improve safety/efficacy for hematopoietic progenitor cell transplantation recipients. Bone Marrow Transplant 2004; 33: 979-987.

22 Chiesa R, Cappelli B, Crocchiolo R, Frugnoli I, Biral E, Noe A et al. Unpredictability of intravenous busulfan pharmacokinetics in children undergoing hematopoietic stem cell transplantation for advanced beta thalassemia: limited toxicity with a dose-adjustment policy. Biol Blood Marrow Transplant 2010; 16: 622-628.

23 Sodani P, Gaziev D, Polchi P, Erer B, Giardini C, Angelucci E et al. New approach for bone marrow transplantation in patients with class 3 thalassemia aged younger than 17 years. Blood 2004; 104: 1201-1203.

24 McDonald GB, Hinds MS, Fisher LD, Schoch HG, Wolford JL, Banaji M et al. Veno-occlusive disease of the liver and multiorgan failure after bone marrow transplantation: a cohort study of 355 patients. Ann Intern Med 1993; 118: 255-267.

25 Przepiorka D, Weisdorf D, Martin P, Klingemann HG, Beatty P, Hows J et al. 1994 Consensus conference on acute GVHD grading. Bone Marrow Transplant 1995; 15: 825-828.
26 Fukuda T, Hackman RC, Guthrie KA, Sandmaier BM, Boeckh M, Maris MB et al. Risks and outcomes of idiopathic pneumonia syndrome after nonmyeloablative and conventional conditioning regimens for allogeneic hematopoietic stem cell transplantation. Blood 2003; 102: 2777-2785.

27 Bourgeois S, Labuda D. Dynamic allele-specific oligonucleotide hybridization on solid support. Anal Biochem 2004; 324: 309-311.

28 Zhong S, Wyllie AH, Barnes D, Wolf CR, Spurr NK. Relationship between the GSTM1 genetic polymorphism and susceptibility to bladder, breast and colon cancer. Carcinogenesis 1993; 14: 1821-1824.

29 Masood N, Kayani MA. Protection against laryngeal and pharyngeal carcinoma: heterozygous vs. homozygous deletions of GSTM1 and GSTT1. Genet Mol Biol 2013; 36: 1-6.

30 Stephens M, Smith NJ, Donnelly P. A new statistical method for haplotype reconstruction from population data. Am J Hum Genet 2001; 68: 978-989.

31 Bredschneider M, Klein K, Murdter TE, Marx C, Eichelbaum M, Nussler AK et al. Genetic polymorphisms of glutathione S-transferase A1, the major glutathione S-transferase in human liver: consequences for enzyme expression and busulfan conjugation. Clin Pharmacol Ther 2002; 71: 479-487.

32 Sabloff M, Chandy M, Wang Z, Logan BR, Ghavamzadeh A, Li CK et al. HLA-matched sibling bone marrow transplantation for beta-thalassemia major Blood 2011; 117: 1745-1750.

33 Morel F, Rauch C, Coles B, Le Ferrec E, Guillouzo A. The human glutathione transferase alpha locus: genomic organization of the gene cluster and functional characterization of the genetic polymorphism in the hGSTA1 promoter. Pharmacogenetics 2002; 12: 277-286.

34 Coles BF, Morel F, Rauch C, Huber WW, Yang M, Teitel $\mathrm{CH}$ et al. Effect of polymorphism in the human glutathione S-transferase $\mathrm{A} 1$ promoter on hepatic GSTA1 and GSTA2 expression. Pharmacogenetics 2001; 11: 663-669.

35 Johnson L, Orchard PJ, Baker KS, Brundage R, Cao Q, Wang X et al. Glutathione S-transferase A1 genetic variants reduce busulfan clearance in children undergoing hematopoietic cell transplantation. J Clin Pharmacol 2008; 48: 1052-1062.

36 Gaziev J, Nguyen L, Puozzo C, Mozzi AF, Casella M, Perrone Donnorso M et al. Novel pharmacokinetic behavior of intravenous busulfan in children with thalassemia undergoing hematopoietic stem cell transplantation: a prospective evaluation of pharmacokinetic and pharmacodynamic profile with therapeutic drug monitoring. Blood 2010; 115: 4597-4604.

37 Miyagi SJ, Brown IW, Chock JM, Collier AC. Developmental changes in hepatic antioxidant capacity are age-and sex-dependent. J Pharmacol Sci 2009; 111: 440-445.

38 Srivastava A, Poonkuzhali B, Shaji RV, George B, Mathews V, Chandy M et al. Glutathione S-transferase M1 polymorphism: a risk factor for hepatic venoocclusive disease in bone marrow transplantation. Blood 2004; 104: 1574-1577.

39 Elhasid R, Krivoy N, Rowe JM, Sprecher E, Adler L, Elkin H et al. Influence of glutathione S-transferase $\mathrm{A} 1, \mathrm{P} 1, \mathrm{M} 1, \mathrm{~T} 1$ polymorphisms on oral busulfan pharmacokinetics in children with congenital hemoglobinopathies undergoing hematopoietic stem cell transplantation. Pediatr Blood Cancer 2010; 55: 1172-1179.

40 Gaziev J, Isgro A, Mozzi AF, Petain A, Nguyen L, lalongo C et al. New insights into the pharmacokinetics of intravenous busulfan in children with sickle cell anemia undergoing bone marrow transplantation. Pediatr Blood Cancer 2015; 62: 680-686.

41 Zwaveling J, Press RR, Bredius RG, van Derstraaten TR, den Hartigh J, Bartelink IH et al. Glutathione S-transferase polymorphisms are not associated with population pharmacokinetic parameters of busulfan in pediatric patients. Ther Drug Monit 2008; 30: 504-510.

42 Hassan M, Ljungman P, Ringden O, Hassan Z, Oberg G, Nilsson C et al. The effect of busulphan on the pharmacokinetics of cyclophosphamide and its 4-hydroxy metabolite: time interval influence on therapeutic efficacy and therapy-related toxicity. Bone Marrow Transplant 2000; 25: 915-924.

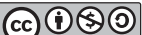

This work is licensed under a Creative Commons AttributionNonCommercial-ShareAlike 4.0 International License. The images or other third party material in this article are included in the article's Creative Commons license, unless indicated otherwise in the credit line; if the material is not included under the Creative Commons license, users will need to obtain permission from the license holder to reproduce the material. To view a copy of this license, visit http:// creativecommons.org/licenses/by-nc-sa/4.0/

Supplementary Information accompanies this paper on Bone Marrow Transplantation website (http://www.nature.com/bmt) 